\title{
Analysis of Employees Compensation and Performance Appraisal Policies in Oromia, Ethiopia
}

\author{
Terecha Bekele Beri, Fikru Tafese, Tesfaye Dagne \\ Department of Health Economics, Policy and Management, Jimma University, Jimma, Ethiopia \\ Email address: \\ terecha650@yahoo.com (T. B. Beri) \\ To cite this article: \\ Terecha Bekele Beri, Fikru Tafese, Tesfaye Dagne. Analysis of Employees Compensation and Performance Appraisal Policies in Oromia, \\ Ethiopia. International Journal of Chinese Medicine. Vol. 3, No. 1, 2019, pp. 7-16. doi: 10.11648/j.ijcm.20190301.12
}

Received: May 1, 2019; Accepted: June 5, 2019; Published: June 26, 2019

\begin{abstract}
Compensation includes salaries and benefits in financial and non-financial forms. The compensation policy was highly linked to that of performance appraisal result. Hence, equitable salary and benefits schemes are prerequisites to effective retention of employees. The aim of the study is to assess the human resource for health compensation and performance appraisal policies and practices. The study employed qualitative case-study design and in-depth-interview and document review data collection methods. The study found base salary and benefits namely incentives package (professional hazards/risk, top up, duty, house allowance and position fee), compensatory leaves, per diem pay, training and education opportunity, promotion, transfer, job injury benefits, compensatory leaves, medical benefit, social security and uniform allowance were enforced. And also it found that the employee appraisal activities intended to be 3600 evaluation: manager, self, team members and customer performance evaluation dimensions. However, organization cars, mobile phones, cheap loans, extra vacations, gifts, travel expenses, vouchers, saving schemes, holiday expenses, and paternal leave were not in practice. Finally, it is recommended that Oromia National Regional State Policy makers should amend the civil servants proclamation to meet the nowadays circumstance. Along with the proclamation, it should formulate regulations and directives on compensation and performance evaluation to enhance consistent decision making at all levels.
\end{abstract}

Keywords: Terecha, Policy, Compensation, Performance Appraisal, Ethiopia

\section{Introduction}

Human resource is one of the factors of production (Labor, Land and Capital) and one of six building blocks of healthcare system. It is the source of achieving competitive advantages because of its capability to convert the other [1-7].

Human resources management is the integrated use of procedures, policies, and practices: Acquisition, Retention and maintenance and Separation. In this context, the pillars of effective human resources management are systems, policies and management and leadership practices $[1,8]$.

Compensation can be direct and indirect financial and nonfinancial categories. Financial compensation includes equitable salaries and benefits. The benefit common types are fair commission, merit increases/performance bonus, paid absence (vacation, holidays, sick leave, maternal/paternal leave, and annual leave), and social security benefits (retirement plan, employment insurance, study arrangements/training and funding of education), company cars, mobile phones and computers, cheap loans, income protection, daycare/child care, stock options, gifts, travel expenses, vouchers, saving schemes, holiday expenses, subsidized meals and clothing allowances. And non-financial compensation encompasses interesting duties and responsibilities (authority and autonomy), opportunity for recognition, feeling of achievement, advancement opportunity, fair and consistent practices and policies, competent supervision, fun and effective co-workers and flexible scheduling or working hours. Hence, equitable compensation and benefits scheme, workplace safety, employee development programs, enabling work environment, and employee relation programs are prerequisites to effective retention of employees [1, 9-11].

Performance appraisal is the process by which immediate managers and team leaders measure the actual performance of employees, compare it with planned performance, document it and provide feedback to employees on their success [12-13].

Performance appraisal can play important role in reward elements including base pay, contingent pay, employee 
benefits, and non-financial pays (intrinsic-in form of recognition) from the work. Performance based pay may increase with increasing rate of the best performance. Sound performance appraisal implementation results in advantages for both employer and employees [12, 14-18].

Human resource policies should reflect sound practice, be written down, be communicated across the organization, and reviewed and modified periodically to reflect changing circumstances. The common/essential human resource policy areas include recruitment policies and procedures; compensation, benefits and reward policies; promotion policy; transfer policy; employee relations policy; performance appraisal policy; grievance policy; termination policy; dismissal policy; retirement policy and occupational health and safety policy [1].

Policy practice can be influenced policy itself, its formulation and dissemination; social, political and economic context; leadership for policy implementation; stakeholder involvement in policy implementation; implementation planning and resource mobilisation; operations and services; and feedback on progress and results. Therefore, it depends on content, process and context, and actors (Policy Triangle) $[1,19-21]$.

\subsection{Statement of the Problem}

Globally, health workers compensation was different country to country [22].

Poorly implemented performance appraisal can lead to employees quit due to results; false or misleading information utilization; lowered self-esteem; wasted time and money; damage of relationships; decrement in motivation to perform; and employees suffer from job burnout and job dissatisfaction. There is increased risk of litigation; managers are required to use an unjustified amount of resources; standards and ratings vary and are unfair; biases can replace standards [18].

In practice, there are many possible errors or biases in the performance appraisal process mostly caused by raters. These errors affect the objectivity of the appraisal very much [16].

World Health Organization (WHO) African countries office (2006) reported that many of human resource for health policies, strategies and plans have not been implemented due to lack of financial support, commitment and policy context [23].

In Zimbabwe, women working in the health sector often receive lower salaries and have fewer opportunities than their male colleagues to rise to the higher position levels of the hierarchy [24]

Ethiopia has faced poor motivation, retention and performance appraisal system, implementation of employee benefit covered by policies due to limited investment into human resource management (HRM) capacity development $[7,25,26]$.

Gambella and Benishangul Gumuz Regional States health workers were discouraged by low salary, poor incentives, poor working condition, inadequate resources to work limited career opportunities, limited training opportunities, hot weather condition, distance from the capital city and poor living condition [27, 28]. Lack of financial reward, empowerment, recognition and clean hospital environment affected health workers satisfaction in Amhara Regional State. Both financial and non financial incentives were not exercised in the referral and district hospitals [29]

Addis Ababa hospitals do not supply transportation service for health workers. There was no a long term training opportunity given to nurses. Most of the time doctors had a chance for specialty training by taking sponsorship from the hospitals [30].

In Oromia hospitals, nurses were de-motivated due to lack of incentives; payment of duty for doctors is much higher 2.5 times than for all health care providers which were 50-60 Ethiopian birr (ETB) for doctors. And all health professionals (HPs) aggrieved due to lack of training and learning opportunities, low new entrants and educational upgraded salary scale, evaluation based carrier development and rewarding system, lack of means of transportation for professionals reside out of the hospital, and social infrastructure such as water and electric light supply in the hospital [31-35].

\subsection{Significance of the Study}

The result of this study will be used as information gap filling by Oromia Regional Health Bureau decision-makers to encourage health system organizations implementing the policies aligning employees and organization goals/values in consistent decision-making. It will inform the health workforces their rights and obligation. Finally, it will be literature for future researchers on similar study.

\subsection{Literature Review}

Sufficient evidences were lacking on analysis of health worker compensation and performance appraisal policies and practices in Ethiopia and globally. Hence, some related unpublished literatures and guides documents were reviewed.

Employee compensation system based on expectancy of employees, comparable with market packages, competency based, and performance based, benefit sharing, covering both financial and non-financial is positively correlated with perceived organizational performance [36].

A study conducted in Bangladesh (2015) shows that there was financial incentives for health workers working in selected three rural districts of the Chittagong Hill Tracks (33\% of total basic salary, not exceeding Bangladeshi Taka 3,000 or USD 38) and not applied to other areas of the country. However, because it seems quite low compared to the current market, it could not attract and retain health workers. To be effective, it was suggested that financial incentives should complement with basic infrastructure available and better living environments and working conditions (road accessibility, communication, electricity, running water, internet, and schools for children, and availability of appropriate accommodation) can significantly improve attraction of health workers [37]. 
Republic of South Africa set minimum and maximum workers basic salary and benefits policy during the year 2008[38]:

Lower Salary Level 1 position salary scale in Rand 42,663-47,583, service bonus 3,555.25, housing allowance 6,000 , employer contribution to medical scheme 26,100 and government employees pension fund (GEPF) of $13 \%$ employer contribution 5,546.19-6,185.79. Totally it accounted for $83,864-89,834$ per year.

And higher salary level 10 position salary scale in Rand 217,483-252,483, service bonus-18,123.5- 21,040.25, housing allowance 6,000 , employer contribution to medical scheme 26,100, and government employees pension fund (GEPF of 13\% employer contribution) 28,272.66-32,822.79. Totally it was $295,978-338,446$ per year.

Republic of Kenya, July 2017, set relatively best minimum and maximum ceiling workers basic salary scale and benefits package, [40]:

Public servant lower job grade 'A' salary scale was $11,840-12,510$ and higher job grade ' $\mathrm{T}$ ' salary scale 160,600 315,700 per month

The public servants allowances and benefits declared by the Kenyan were as follows:

Health workers allowance, excluding HPs assigned at administrative positions, per month in Kenyan shilling are Emergency call allowance for all medical doctors (medical officers, dentist and pharmacist) 30,000; Extraneous allowance for all human resource for health at healthcare facilities, except drivers rather than hospital, at urban 5,00040,000 , at Rural was 5,000-35,000 and hardship area 8,00040,000; Health risk allowance for all HPs 2,000-20,000; Non-practicing allowance for medical officers, dentist and pharmacist 12,000-60,000; and Uniform allowance for all Nurses 10,000 per year.

Allowance in the public service are house allowance for all public servants 2,250-100,000; hardship allowance for all public servants 2,800-60,000; daily subsistence allowance for government officers to attend to official assignment away from their duty station within the country and out of the country: local travel 2,100-12,000 and foreign travel in 13200-129,700; and Car loan and mortgage schemes for all state officers who either full time or part-time basis and other public officers who are permanent and pensionable basis: car loan at 3\% interest for 4 years 600,000-4,000,000 and Mortgage at 3\% interest for 20 years 4,000,000-20,000,000.

Medical schemes for public officers per annum, for Public officers (employee or principal member) and a spouse and four dependent children under age of 24 , with exception of school children and disability of above 24 age: In-patient cover 750,000-2,000,000, Outpatient cover 100,000-250,000, Maternity cover 50,000-150,000, Dental cover 30,000 and Optical cover 15,000-35,000.

Major objective is to assess the human resource for health compensation and performance appraisal policies and practices in Oromia Regional Health Bureau. Specifically, it is:

1. To identify human resource for health compensation policies contents

2. To identify human resource for health performance appraisal policies contents

3. To analyse human resource for health compensation policies contents and practices

4. To analyse human resource for health performance appraisal policies contents and practices

\section{Methods and Materials}

\subsection{Study Area and Period}

The study area was Oromia Regional Health Bureau (ORHB) where the study was conducted from March $27 / 2018$ to June $11 / 2018$.

\subsection{Study Design}

The study employed qualitative Case-study design. The cases were health workers compensation and performance appraisal policies.

\subsection{Sampling Technique}

The study employed purposive sampling technique for interview and all available policy document review. Twenty one sample size was designed to follow information saturation.

\subsection{Data Collection Techniques}

The qualitative data collection methods namely document review checklist and interview guides were used. The checklists and guiding questions were developed by the investigator after reviewing different literatures and administered same. The tools were translated to Afan Oromo, working language of the region, and back to the English version.

\subsection{Data Analysis}

Data obtained by document review, and interviews captured using the voice recorder was transcribed verbatim each day. The qualitative data analysis methods, transcription, coding, categorizing, thematizing and narration, were conducted manually.

\subsection{Ethical Consideration}

Ethical clearance was obtained from Jimma University and ORHB Institutional Review Boards to commence the study. And consents of the participants were obtained orally and confidentiality was secured by coding interviewees. The organization confidentiality was also secured.

\section{Results}

\subsection{Socio-Demographic of the Interviewees}

All available policy documents were reviewed and fifteen key-informants were interviewed. 
Out of the fifteen interviewed key-informants, six were second and nine were first degree holders. Three of them were women and twelve were males. By the position they held, two were deputies or vice heads, four directors, four job process coordinators, four human resources for health management experts and one human resources for health management consultant. The age of the participants ranged from 30 to 55 years.

The study results obtained by the policies document review and in-depth interview results were merged and presented together by quoting the words of the interviewees.

\subsection{Human Resource for Health Compensation Policies and Implementation}

\subsubsection{Employees' Salary Scale}

There were two types (HPs and social workers) of health worker salary scales using seven job grades: Afan Oromo word equivalent to guard and labour (EH), Artisan (OH), Secretariats and Accountant $(\mathrm{BH})$, semi-professional (PG), administration (BU), Professional Science (PS) and Level I$\mathrm{V}$ for HPs and Social Workers. EH and PS were the minimum and maximum job grades respectively. Social workers minimum grade EH valued as 680-2,197ETB; and PS valued as $2,748-10,946 \mathrm{ETB}$ of ceiling salary scale. And the HPs salary scale minimum to maximum was PG valued as 1,511-7,647ETB and PS valued as 3,653-18,425ETB salary scale ceiling.

The employee compensation policy declared that all positions of equal value shall have equal base salary without any discrimination. However, human resource for health (HPs and social workers) was paid differently by different salary scale working in the same sector, even at the same position, HPs paid better salary. For instance, a female interviewee said, “... a HP degree and social degree have no equal base salary working at the same position. In health sector, I think the degree of social worker is not known as degree. The career structure and benefits allowed to HPs, but excluded social workers. This caused employees' job dissatisfaction." And a male interviewee said, “...HPs and other professional salary is not the same. It is determined based on field of education. HPs do elapse four years in college and others three years. The service they rendering is also the vital; HPs serve patients and feel humanity."

\subsubsection{Periodical Increment of Salary}

Oromia civil servants proclamation of 2002 declared, 'Civil servants may be entitled to periodical salary increments based on their performance evaluation results...' However, there was no time limitation included in the policy when the salary increment shall be done. And there was the only HPs career structure in form of periodical salary increment in two service year interval while that of social workers periodical salary increment was not implemented yet. For instance, a male interviewee said, “... HPs are entitled to career structure based on criteria: two service year intervals, performance evaluation result, professional title and license, and one research published on accredited journal for specialist HPs. " Another male interviewee said, "...administration workers wait for salary scale improvement and have no right to ask periodical salary increment, because there is no regulation and directive obliging the periodic salary increment and it is unfairly denied..."

The HPs Career Structure Criteria were Professional License/Title, Performance appraisal (The average of three times Performance appraisal result to upgrade professional title from Junior to Professional was $70 \%$, Professional to Senior $71-75 \%$, Senior to Chief $76-79 \%$ and above of chief $80 \%$ and more), experience, education status, and research published on accredited journal (specific to higher HPs or specialists).

\subsubsection{Allowances and Incentives}

The incentive package was concerned selective HPs working only in Hospitals and Health Centers. It includes professional hazards/risk, top up, duty-on-duty and on-call, house allowance, position fee paid monthly in cash, and Private Wing medical service in hospitals.

The Top up concerned all health medical specialists and General Practitioners, 2000 ETB and 1000 ETB respectively. House Allowance allowed to all specialists, General Practitioners $\mathrm{s}$ and Integrated Emergency Surgery officer /IESO equally 1000 ETB. Professional Hazard/ Risk incentive allowed for Specialist of Surgeon, Gynecologist, IEESO, Emergency specialist, Orthopedics specialist, Emergency Surgeon specialist, General Practitioners, Clinical Pathologist, Anesthologist specialist and professional, and Radiology specialist was 1225 ETB and midwife, delivery room serving Nurse, all diploma anesthesia professionals, psychiatry professionals, X-ray diploma and degree professionals, emergency medical technicians and nurses serving Intensive Care Unit (ICU) and triage rooms was 470 ETB. HPs Duty was allowed for worked time out of the regular working hours: night, weekend and holiday. The duty payment was calculated worked hours multiplied by hourly salary to be paid at the end of the month.

On-duty was applied Monday to Friday from 5:30 pm evening to 8:30 am morning (Night Duty) paid for 7 hours per day. Weekend and holidays paid for 15 hours per day for night duty and 8:30 am morning to $11: 30 \mathrm{pm}$ evening paid for 8 hours per day. HPs on-duty shall be off in the next day. However, HPs working in hospitals less than $50 \%$ physician standard, General Practitioners on night duty could not be given off and shall serve up to 12:30 am morning and paid 11 hours per day. On-call was applied for the recorded worked hours daily and summarized monthly. Its compensation was calculated with his/her hourly salary. If $\mathrm{s}$ /he was not called, then shall be paid $30 \%$ of daily pay. If $\mathrm{s} / \mathrm{he}$ was assigned from $11: 30 \mathrm{pm}$ evening to 2:30am morning and do not called, s/he would be paid 5 hours and not be off. If assigned from 2:30 am morning to 11:30 pm evening on weekend and holiday and was not called would be paid 2:40 hours per day. There was duty policy violation. For instance, a male interviewee said, "... there is problem with assignment of 
On-call Professionals as on-duty and on-duty as on-call. Even there is illegal pay of duty. I know an on-call Hp worked for 2 hours and was paid 15 hours in a hospital."

The work uniform/cloth allowance was for the puprpose of the work not thought of employees' benefit.

It was allowed for health workers assigned to some specific positions and HPs in kind, not in cash payment: guards, messengers, cleaners and HPs caring for patients (Doctors, Public Health Officers, Nurses, Pharmacist, Blood analyst, Laboratory Technicians, X-ray technicians, Radio Therapist, Medical Technicians). The type of the uniform to be provided were coat, trousers, shirts, jacket, dress, cape, silk overcoat, female under wear and rain coat, and shoes. It was obligatory to wear the uniform during regular working hours, unless disciplinary penalty may follow by policy violation. For instance, a male interviewee said, “...work uniform clothing is compulsory and supplied for some position and HP twice a year."

\subsubsection{Position Fee}

It was paid for assignee at Hospitals and Health centers administrative positions. Chief Executive Officer (CEO) was paid 900 ETB, 1200 ETB and 1500 ETB at District Hospital, Zonal Hospital and Referral Hospital respectively; Medical Director was paid 700 ETB, 1000 ETB and 1300 ETB at District Hospital, Zonal Hospital and Referral Hospital respectively; And PHCU director at Health Center was paid 470 ETB per month. Emergency, outpatient department (OPD) and Inpatient department (IPD) Service Aspect heads were paid 500 ETB, 700 ETB and 900 ETB at District Hospital, Zonal Hospital and Referral Hospital respectively per month. Medical, Gyn., Pediatrics, Surgical, Orthopedics, Dental, Ophthalmology, Physiotherapy, Psychiatry and Multi Drug Resistant Tuberculosis (MDR-TB) Ward Heads were paid 300 ETB, 500 ETB and 700 ETB at District Hospital, Zonal Hospital and Referral Hospital respectively per month. Matrons were paid 400 ETB, 600 ETB and 800 ETB while vice matrons were paid $300 \mathrm{ETB}, 400 \mathrm{ETB}$ and $650 \mathrm{ETB}$ at District Hospital, Zonal Hospital and Referral Hospital respectively. Medical, Pediatrics, Obs. gyn, Surgical wards Head Nurse, Neonatal and adult ICU, Emergency unit and Operation unit head nurse, and X-Ray, Pharmacy, Laboratory, Delivery, Mother and Child Healthcare, ART and Triage Team Coordinator were paid 200 ETB, 300 ETB and 350 ETB at District Hospital, Zonal Hospital and Referral Hospital respectively per month.

There was also Private wing medical service in hospitals intended as specialist health professional retention mechanism. For instance, a male interviewee said, “...hospital Private wing medical service is retention mechanism of specialists HPs and is initiated in Oromia. It is being executed during out of regular working hour 12:30 am$1: 30 \mathrm{pm}$ afternoon and 5:30-7:00pm evening. The income generated from the medical services is shared to HPs $70 \%$, from the left $30 \%, 15 \%$ goes to the managers and social worker participated at that time. Doing so, the HPs incur no cost, the costs covered by government."

\subsubsection{Per Diem Compensation}

Per Diem compensation was aimed to cover out of pocket expenses due to field work, to conduct meetings, and training of workers. It was categorized into government Regular Budget and Development Assistant Groups (DAG) budget, also called Fund. Similarly, the per diem is divided into employees and government officials payment scales which were not the same. A male interviewee said, “... there are two types of per diem scales in our Bureau: regular budget and fund budget per diem scales...'

Regular government budget per diem was categorized as the Employees and government official per diem compensation scale.

It was allowed for employees as per salary scale. Accordingly, the minimum per diem per day 93 ETB at Woreda and woreda towns and the maximum is 206 ETB per day at Addis Ababa and Special Zones Surrounding Finfine in Oromia and 210ETB and 300ETB regular government and fund budget respectively. However, Government officials were allowed special per diem payment scale minimum 305 ETB and maximum $750 \mathrm{ETB}$ and $50 \%$ of the total payment for pension/accomodation based on the receipt they present at woreda level for both budgets.

For instance, a male interviewee said, “...regular budget per diem scale is not the same for all workers for it is paid based on workers' salary scale as the rate set prior, and the fund budget per diem scale is the same for all employees. Per Diem for both regular and fund budgets is paid as especial compensation for government officials based on receipts they present..."

\subsubsection{Employees Promotion and Transfer}

The Oromia Civil servant proclamation of 2002 declared that every civil servant who completed his probation could compete for promotion. However, competitors of the job process position and sector head by merit that were believed competent were used to be identified by the sector head and authorized responsible body respectively, and communicated to the promotion committee for selection-every employee had no right to compete.

The competition criteria among employees were service year $10 \%$, education preparedness $10 \%$ Performance appraisal result $51 \%$, written exam or practice $24 \%$ and discipline $5 \%$, vacant position availed, allocated budget and planned promotion in the budget year. The criteria set by percentage had breakdown to share the portion for competition.

There was problem in Women Engagement or empowerment through promotion. For instance, a female interviewee said, "...females are not benefited equally with males. Women are ignored to be assigned at higher position at which salary increases with it, because government officials assigning males without competition between males and females."

The payment or the salary of the new position was limited to 1-3 stage from the prior position salary for Diploma $(10+3) /$ Level III holders and above, and 1-6 stage for less 
than Diploma $(10+3) /$ Level III holders. The position salary improvement concerned social workers for HPs were collecting career structure other than position change. For example, a female interviewee said, “...social workers have promotion with salary increment while HPs have career structure."

Internal and external employee transfer was implemented based on competition among interested employees, job requirement and health workers transfer specific policy. For instance, a male interviewee said, "...employee transfer is administered by health sector specific human resource for health transfer policy. However, the general Oromia civil servant transfer policy is applied between regions."

The employee transfer policy criteria were marriage, sickness supported by hospital medical board evidence, experience, employee-by-employee, exceptional life threaten cases and social problems which had different weights. However, there were problems with implementation of the policy. For example, a male interviewee said, “...health worker specific transfer policy is not being implemented as intended for there is unfair transfer."

\subsubsection{Regular Working Hours and Office Hours}

The regular working hours of civil servant was declared to be determined on the basis of the conditions of their work and shall not exceed 40 hours a week. However, there was neither regular working hour regulation nor directive limiting the entrance and exit, tea break and lunch time. For example, a male interviewee said, “...still there is no regular working hour policy. Based on habit, we enter at 8:30am morning, exit at 6:30 am for lunch, come back at 7:30 pm afternoon, and exit 11:30pm. However, it is based on the circumstances of the geographical climate. For example, if you go to Gambella, entrance time is 7:00am morning and exit time is 3:00pm afternoon. Even here at Adama, entrance time is 8:00am morning, exit time for lunch is 12:00am, entrance time after lunch is 1:00pm afternoon and exit time is 5:00pm afternoon..."

Public holiday were declared in generic words that any civil servant had no obligation to work on public holidays and shall incur no reduction in his regular pay. However, there was no specific national holy days policy identified by name, for instance new year, Easter and the like) and similarly, no weekly rest days declared specifically. For example, a male interviewee said, “...we have no policies for holy days and weekly rest days specifically. But we implement holy days based on calendar and Saturday and Sunday weekly rest days."

The compensatory leaves entitled to the workers were annual leave, Sick leave, maternity, job injury, wedding, mourning, examination and maternity leaves were administered as per the events occurred. Specifically, Sick leave required recognised or licensed healthcare institution, either government or private institution written evidence. For example, a male interviewee said, “...every employee has right to be granted annual leave, maternity leave, sick leave including job physical injury leave, wedding leave and mourning leave whenever required. However, medical certificate is required from recognised health institution to grant sick leave. But the accumulated annual leave compensation is not in practice."

Annual leave: Annual leave allowed to civil servant was 20-30 working days in a fiscal year based on the service year annually. The head of a government institution might authorize the postponement of annual leave for two budget years, where the government office, due to compelling reasons, was unable to grant a civil servant his annual leave within the same budget year. Payment for accumulated annual leave was prohibited except for unused annual leave due to termination of appointment and postponed annual leave for two years may be claimed payment half of his accumulated leave in third year. However, the compensation was denied.

Maternity Leave: A pregnant civil servant should be entitled maternity leave for medical examination as per a doctor's recommendation. She was entitled to 30 consecutive days paid leave before, if recommended by a Doctor, and a period of 60 consecutive days after her confinement. However, it ignored the paternity leave to care for the mother and newborn.

Sick Leave: Any civil servant was entitled to sick leave where $\mathrm{s} / \mathrm{he}$ was unable to work due to sickness not exceeding eight months in a year or twelve months in four years. It was granted with full pay for the first three months, half pay for the next three months and without pay for the last two months based on medical evidences.

Leave for Personal Matters: Any civil servant was entitled to leave mourning, wedding, examination and the like for a maximum of three consecutive days.

Medical Benefits: Principal permanent civil servants were entitled to all medical services free of charge and with $50 \%$ discount for his spouse and minor children in government medical institution for some contribution from pay roll. However, it lacked implementation. A male interviewee said, "...even if there is policy, Human Resource for Health medical benefit is not implemented yet."

\subsubsection{Job Injury Medical Benefits, Compensation and Injury Leave}

The government office should cover the necessary medical expenses incurred by a civil servant due to employment injury. Any civil servant who had sustained an employment injury should be entitled to leave with pay until he recovers and resume work or until it was medically certified that he or she was permanently disabled not exceeding 12 months. A civil servant who was unable to recover and resume work within 12 months or his survivors declared to be entitled to the benefits of disability pension (permanent worker) and temporary workers should be entitled to compensation amounting to 5 times of his annual salary. However, the workers job injury medical expenses and disability compensation and pension were not implemented. For example, a male interviewee said, "...job injury medical benefit and injury disability compensation is not implemented yet." 


\subsubsection{Health Workers Training and Education Opportunity}

The policy covered long-term and short-term training (Inservice Training) and college tuition opportunities nationally and internationally by government sponsorship. However, there was no enforcing specific policy to decide on base salary after graduation for both HPs and social workers. For instance, a male interviewee said, “...the initial salary for HPs educational up-grade who has four service years before joining university or college and upgraded from diploma to first degree is being assigned to PS 3/1, from first degree to second degree is assigned to PS 4/1 and from second degree to third degree (Specialist HP) is assigned to PS 8/1. In special case, if the employee stepped above the upgrading by career structure, then nothing will be added and continue earning the previous salary. The cut point of service year is four year and no experience is considered during the regular time the employee elapsed in college except non regular programs attendants.'

\subsubsection{Retirement Pension}

A public servant who had completed at least 10 years and separated from the service by voluntary resignation or for any other cause other than disciplinary action should receive retirement pension for life upon attaining retirement age of 60 not less than $30 \%$ of his average salary for the last three years preceding retirement and should be increased for each year of service beyond10 years by $1.25 \%$. The retirement pension may not exceed $70 \%$ of the average salary. A public servant who has not completed 10 years of service and retired on attaining retirement age should receive gratuity amounted to his salary for 1.25 month preceding retirement multiplied by the number of years of service. A public servant who separated from the service after completing at least 25 years of service should receive retirement pension for life beginning with five years prior to retirement age. Old age pension policy was exactly implemented as per the Federal retirement law. For instance, a male interviewee said, "...workers retirement pension is being granted whenever a permanent employee fulfilled the criteria by concerning law. However, the job injury disability retirement pension compensation was not implemented."

\subsection{Health Workforce Performance Appraisal Policies and Implementation}

There was no employee performance appraisal policy formulated by authorized body, but manual with checklist except HPs selective specific performance appraisal policy developed by ORHB. For example, a male interviewee said, “... there is worker performance evaluation system manual as a general and specific HPs performance appraisal policy..."

There was no specific job standard/job specification and job description identified by law, except the one included in Business Process Reengineering manual and failed to contain measurement dimensions: volume, quality, cost and time for each individual workers. Example, a male interviewee said “...we could not set standard for all jobs which limits workers scope of responsibility and therefore plan was preferred as standard, because there was no legal ground to set standard for each job. Due to this, some employees were rejecting to accept individual activities plan managers share them." In addition, another male interviewee said, “... even in Oromia, there is no complete and scientific employee job description declared by law in Ethiopia...."

It was declared that outstanding performance can be awarded. However, there was no implementation. For instance, a female interviewee said, “...even if the Strategy Plan Result Evaluation System manual embraces awarding component, the performance based compensation is not implemented yet."

The employees' performance appraisal was intended to be $360^{\circ}$ : performance evaluation by immediate manager $(50 \%)$, self (10\%), Customer (20\%) and Team evaluation (20\%).

Rural Health Extension Workers should be evaluated achieving health extension package working with Health Development Army. Health Centers level Nurses, and public Health Officers supporting HPs should be evaluated 50\%, midwives 20\%, and Primary Healthcare Unit (PHCU) Director $60 \%$ according to this policy and the left by Strategy Plan Result Evaluation System.

It was declared that the level of achievement of performance appraisal results were outstanding $(90 \%$ and above); very high (80-89\%); high (65-79\%); satisfactory (50$64 \%$ ); and unsatisfactory (less than 50\%).

There was challenge in employee actual performance evaluation. For example, a male interviewee said, “...the performance appraisal policy implementation is not the same at all levels..." Another male interviewee said, “... for it is subjective, there is no right performance appraisal based on plan and actual performance of employees; it is give and take system

The employee performance evaluation system manual stated as "sectoral offices and job processes should facilitate for employees who were evaluated at high and above results (65\% and above) for benefits as per concerned policy of salary increment, award and incentives." However, all interviewees reported that there was no performance based benefit. For instance, a male interviewee said, “...there is no performance based compensation for social workers in practice. There was no time when budget was allocated for the award purpose."

The workers achieved satisfactory (50-64\%) must improve their achievement to high level $(65-79 \%)$ by the next two consecutive performance appraisal, unless they will be demoted one step from the current job grade. The workers achieved unsatisfactory (less than 50\%) should given the capacity building and must improve achievement by the next two consecutive performance appraisal, unless they should be fired from the sector. However, nothing is done yet.

\section{Discussion}

The Oromia Civil Servant proclamation of 2002 lacked 
employees' compensation and Performance appraisal Regulations which made them incomplete and endangered its implementation. The available documents as directives were not passed through the policy formulation steps and procedures of policy triangle to be called as directives for they were availed in circular form $[1,19]$. Most of them were cascaded from Federal Ministries in form of circular letters.

\subsection{Human Resource for Health Compensation Policies}

The compensation policy stated briefly the salary scale. However, there was discrimination of salary scale between HPs and social workers as well as between sectors for similar positions and same activities. HPs were paid better than that of the social workers working at the same position. Even there was unfair salary scale for health institutions card room workers and cleaners in relation to the workloads and their patient contact that is more exposure to risk than others sectors and health office level.

Comparing to that of the Republic of Kenya, and Oromia Finance and Development Cooperation office and Oromia Inland Revenue Authority, the Oromia health workforce salary scale was so low. ORHB paid HPs 1511-14,205 ETB and social workers 860-7647 ETB while Oromia Finance and Development Cooperation office paid 960-11057 ETB and Oromia Inland Revenue Authority paid 1564-11057 ETB [39]. Likewise Republic of Kenya salary scale was 11,840$160,600 \mathrm{~K} /$ Shilling all employees in relation to the assignment to the job grade [40].

The currency exchange of 1 United State Dollar (1USD) was equal to100 Kenyan shilling while 1USD was equal to 27.25ETB in June, 2018. Likewise, 1 Kenya shilling was equal to 0.27ETB. And also gross domestic product (GDP) growth rate per cent was 8.1 and 5.1 for Ethiopia and Kenya respectively in 2017. So, Ethiopia has better capacity to pay citizens than Republic of Kenya [41], [42].

Health workers benefit policies did not cover organization cars, mobile phones and computers, cheap loans, meal checks, income protection, extra vacations, gifts, bonus, travel expenses, vouchers, saving schemes, holiday expenses, subsidized meals, flexible working hours and paternal leave. And the three consecutive days of personal matters leave (mourning, wedding and examination), and maternity leaves (90 days) were not sufficient for the purpose of the new borne baby care for there was no daycare station in public organization, ignoring exclusive breast feeding up to six month (180 days). Regular working hours and office hours were not determined by regulation and directive specifically as intended by the Civil servant proclamation and so it was administered in habit [1], [9], [14].

\subsection{Health Workers Performance Appraisal Policies}

The employee actual performance or planned activities evaluation had no standard to fit the actual performance evaluation checklist in practice and had subjectivity to measure. It lacked actual performance time, cost, quality, quantity and weights for each activity to be performed and measured accordingly. Therefore, it was exposed to errors or biases in all evaluation dimensions (falsification, favoring some employees by give and take approach and harming others intentionally) $[1,38]$. The employee actual performance missed management by objectives (MBO) lacking good characteristics of objective: Specific, measurable, achievable, realistic and time bounded (SMART) $[4,12]$. The employee compensation and performance appraisal intended to have strong interconnection and performance based positive and negative reinforcement. However, it was not implemented [1, 4].

\subsection{Limitation of the Study}

This study was conducted on the employer side only limited to the policies implementers at Oromia Regional Health Bureau level.

\section{Conclusion and Recommendation}

\subsection{Conclusion}

The compensation policy stated briefly the salary scale with its ceiling of periodic increment which was not implemented for the social workers.

Health workers compensatory leaves, medical benefits, employment injury disability pension and compensation, uniform allowance, social security including old age retirement pension, allowances and incentive package and training and education opportunities, and employee transfer policies and promotion contents were covered well.

However, it excluded organization cars, mobile phones and computers, cheap loans, meal checks, income protection, extra vacations, gifts, bonus, travel expenses, vouchers, saving schemes, holiday expenses, subsidized meals, flexible working hours and paternal leave.

Workers performance appraisal held no preset performance evaluation standard and job description except the healthcare centers level which was limited to PHCU and to selected HPs.

\subsection{Recommendation}

Oromia National Regional State Policy makers should formulate regulations and directives on compensation and performance evaluation to enhance consistent decision making at all levels.

The Oromia Public Service and Human Resource Development Bureau should follow up the policies practice to identify their success or failure.

The Oromia Regional Health Bureau must suggest to the policy makers the revision of existing civil servant proclamation and formulation of the non available regulation and directives on the workers compensation and performance appraisal to implement consistently communicating through the hierarchy in health system organization levels.

The next researchers might conduct study at other levels of the health system organization and from the employee side. 


\section{Declaration}

Ethics Approval and Consent to Participant

Ethical clearance was obtained from Jimma University and ORHB Institutional Review Boards to commence the study. And consents of the participants were obtained orally and confidentiality was secured by coding interviewees.

Consent for Publication

I agree with the publication of this thesis

Availability of Data and Material

All required data and materials are available

Authors' Information

Terecha Bekele Beri (MSc in Human Resource Management for health, BA in Management and BSc in Health Service Management)

\section{List of Abbreviations}

WHO: World Health Organization

HRM: Human Resource Management

HP: Health Professional

ORHB: Oromia Regional Health Bureau

EH: Afan Oromo word equivalent to guard and labour

ETB: Ethiopia Birr

BH: Afan Oromo word equivalent to Secretariats and Accountant

BU: Afan Oromo word equivalent to administration

PG: Afan Oromo word equivalent to semi-professional

PS: Professional Science

OH: Afan Oromo word equivalent to Artisan

IESO: Integrated emergency surgery officer

ICU: Intensive Care Unit

CEO: Chief executive officer

IPD: Inpatient department

OPD: Outpatient department

PCHU: Primary Healthcare Unit

MDR-TB: Multi Drug Resistant Tuberculosis

DAG: Development Assistant Groups

USD: United State Dollar

GDP: Gross Domestic Product

MBO: management by objectives

SMART: Specific, measurable, achievable, realistic and time bounded

\section{References}

[1] Ethiopian Ministry of Health. Human Resource for Health Management In-Service Training Guideline; 2014.

[2] World Health Organization. Working Together For Health, World Health Organization Report. Geneva, Switzerland; 2006.

[3] Demeke Assefa, Michael Shiferaw, Dargie Arbsie, Anwar Yiman, Tesfakiros Arbsie, Waju Beyene et al. Human Resource Planning and Development, Human Resource for Health. Jimma: Jimma University; 2014.

[4] Abebaw Gebeyehu, Negalign Berhanu, Mesfin Addisse and
Zeine Abose. Principles and Practices in Public Health, Human Resource for Health. Jimma: Jimma University; 2014.

[5] Karunesh Saxena and Pankaj Tiwari. Human Resource Management Practices: A Comprehensive Review. India: Mohanlal Sukhadia University; 2012.

[6] Edgar Necochea, Manjushree Badlani and Debora Bossemeyer. Systemic Management of Human Resource for Health. USA: Jhpiego; 2013.

[7] Management Sciences for Health. Tools for Planning and Developing Human Resources for HIV/AIDS and other Health Services; 2006.

[8] Fitsum Girma. Human Resources Management. Jimma: Jimma University; 2008.

[9] Michael Armstrong. Human Resources Management Practice Handbook. 7th ed; 1999.

[10] Sylvana Janssen, Asta Benetyte, Lina Pileicikaite, Brigitte König, Evelyne Van Dyck, Anna Puigdecanet and et al. Flexibility of the fringe benefits in the European Union. 2007; 6-7, 11.

[11] The Society for Human Resource Management. A Research Report of Employee Benefits-Remaining Competitive In A Challenging Talent Marketplace; 2017; 1-40.

[12] Michael Armstrong. Performance Management. $3^{\text {rd }}$ Ed. 2006 151-154.

[13] Tenaye Gugsa Indeshaw, Yoseph Tilahun Sahele, Anwar Yiman Wassie, Waju Beyene Salgedo, Mesfin Addisse, Dargie Arbsie et al. Human Resource Performance Management, Human Resource for Health. Jimma: Module of Jimma University; 2014.

[14] Elaine D. Pulakos. Performance Management: A New Approach for Driving Business Results. 2009.

[15] Sait Gürbüz and Onur Dikmenli. Performance Appraisal Biases in a Public Organization: An Emprical Study; 2007.

[16] World Health Organization. Health Policy and Systems Research: A Methodology Reader Edited By Lucy Gilson; 2012.

[17] Trochim, W. M. K. Evaluation policy and evaluation practiceNew Directions for Evaluation. 2009; 17-18.

[18] Herman Aguinis. Performance Management. 2005.

[19] World Health Organization. Health Policy and Systems Research Reader on Human Resource for Health, edited by Asha George, Kerry Scott, Veloshnee Govender; 2017.

[20] Dieleman et al. Human Resources for Health 2011, 9:10http://www.human-resources-health.com/content/9/1/10: Improving the implementation of health workforce policies through governance: a review of case studies.

[21] Assegide Demmise Shishgu, Mahir Jibril Ahmed, Negalign Berhanu Bayou, Michael Shiferaw Zahra Miftah, Zeine Abose Anore et al. Human Resource Policy Formulation, Implementation and Evaluation. Jimma: Module of Jimma University; 2014.

[22] Nele Jensen. The Health Worker Crisis and an analysis of the issues and main international responses. UK: Health Poverty Action; 2013. 
[23] World Health Organization. Policies and Plans for Human Resources for Health, Guidelines for Countries in the World Health Organization African Region; 2006.

[24] Gilles Dussault and Carl-Ardy Dubois. Human resources for health policies: a critical component in health Policies; 2003; 13 .

[25] Ethiopian MoH. Health Sector Transformation Plan / HSTP 2015/16 - 2019/20, 47; 2015.

[26] Ethiopian Ministry of Health. HSDP III 2005/6-2009/10; 2005.

[27] Adugna Endale. Health Professionals' Intention to Leave from Public Health Facilities and Its Determinants in Gambella Region, Southwest Ethiopia; 2012.

[28] Mergia Eshetu. Predictors Of Health Professionals' Intention To Leave Among Public Health Facilities Of BenishangulGumuz Region, West Ethiopia; 2014.

[29] Molla Belay Tessema. Assessment of Employee Satisfaction and Correlates in Public Hospitals, North West Amhara Region; 2011.

[30] Kinfe Haile. Assessment of Factors Affecting the Motivation of Doctors and Nurses in Five Selected Public Hospitals In Addis Ababa; 2012.

[31] Tofik Abajebal. Job Satisfaction and Associated Factors Among Health Professionals Working In West Hararge Zone Public Hospitals, Eastern Ethiopia; 2014.

[32] Kenasa Kumera. Health Professionals Recruitment and Attrition in Oromia Region; 2011.

[33] Ayele Semachew. Job Satisfaction and Factors Influencing it Among Nurses Working In Jimma Zone Public Hospitals, Oromia Regional State, South West Ethiopia; 2014.
[34] Alemshet Yami, Leja Hamza, Alima Hassen, Challi Jira, Morankar Sudhakar. Job Satisfaction and its Determinants Among Health Workers in Jimma University Specialized Hospital, Southwest Ethiopia; 2011. 21 ( Special issue).

[35] Tesfaye et al., J Nurs Care 2015, 4:6 http://dx.doi.org/10.4172/2167-1168.1000312: Assessment of Factors Affecting Performance of Nurses Working at Jimma University Specialized Hospital in Jimma Town, Oromia Region, South-West Ethiopia.

[36] Biniam Kassa. The Impact of Human Resource Management Practice on Organizational Performance; 2016.

[37] Lal B Rawal, Taufique Joarder, Sheikh Md. Shariful Islam, Aftab Uddin and Syed Masud Ahmed. Developing effective policy strategies to retain health workers in rural Bangladesh: a policy analysis. 2015;7-8. Available from DOI 10.1186/s12960-015-0030-6.

[38] Republic Of South Africa. Salaries and Benefits in the Public Service. 2008; available from www.gems.gov.za or email: join@gems.gov.za; www.gepf.co.za / www.gepf.gov.za or email: enquiries@gepf.co.za and www.dpsa.gov.za.

[39] Oromia Finance and Development Cooperation Office and Inland Revenue Authority salary scale, Oromia Public Service and Human Resources Development Letter Reference No WG1-2/21/426 on 13, June 2009EC (2017GC).

[40] Republic of Kenya civil servant Salary and Remuneration Commission, available from www.src.go.ke, 2017.

[41] African Development Bank. East African Economy Outlook 2018, available from www.afdb.org $>$ afdb $>2018$ AEO.

[42] Federal Civil Servant proclamation No 515/2007. 